\title{
Effect of vapor-induced phase separation on the morphology and separation performance of polysulfone hollow fiber membranes
}

\author{
H.A. Tsai ${ }^{\mathrm{a}, \mathrm{b} *}$, J.H. Lin ${ }^{\mathrm{b}}$, D.M. Wang ${ }^{\mathrm{c}}$, K.R. Lee ${ }^{\mathrm{b}}$, J.Y. Lai $^{\mathrm{b}}$ \\ ${ }^{a}$ Department of Material and Fiber, Nanya Institute of Technology, Chung-Li, Taiwan \\ Tel.+88634361070 ext.4101; Fax+88634651975; email: huian@nanya.edu.tw \\ ${ }^{b} R \& D$ Center for Membrane Technology, Chung Yuan University, Chung-Li, Taiwan \\ ${ }^{c}$ Department of Chemical Engineering, Taiwan University, Taipei, Taiwan
}

Received 20 October 2005; accepted 1 March 2006

\section{Introduction}

The applicability of a membrane technique to a separation process strongly depends on whether the membrane possessing suitable separation performance can be successfully prepared. Among the methods for preparation of membranes, the most widely used one is the phase inversion method [1]. There are several methods to induce phase separation during membrane forming, such as thermally induced phase separation (TIPS), nonsolvent induced phase separation (NIPS), and vapor-induced phase separation (VIPS) [1].

Although the role of VIPS in the formation of flat-sheet membranes was widely studied $[2,3]$, few articles identified the importance of VIPS in the preparation of hollow fiber membranes. In the present work, we fabricated polysulfone (PSf) hollow fiber membranes via the dry/wet spinning process, changing the ambient humidity to demonstrate the effect of VIPS on membrane morphology. Our focus is on how VIPS affects the formation of macrovoids near the outer surface of hollow fibers and the pervaporation performance of $90 \mathrm{w} \%$ aqueous isopropanol solution through VIPS fabricated PSf hollow fiber membranes.

\section{Results and discussion}

\subsection{Effect of air gap on the morphology of PSf hollow fiber membranes}

Fig. 1 depicts the morphology of the hollow fiber fabricated by varying the air gap, when the relative humidity was kept at $90 \%$. The results indicate that the length of air gap affects dramatically the morphology of hollow fibers: macrovoids were clearly seen with no air gap, but totally disappeared with an air gap of $5 \mathrm{~cm}$, reappeared when the air gap increased to $10 \mathrm{~cm}$, and could no longer be seen when the gap was more than $30 \mathrm{~cm}$. Table 1 reveals the relationship between macrovoids and air gap under different relative humidity. It shows that with higher relative humidity in

\footnotetext{
*Corresponding author.
} 


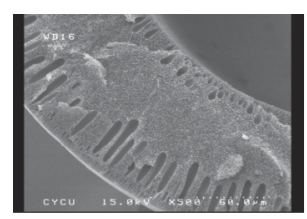

(a)

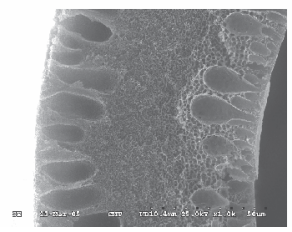

(e)

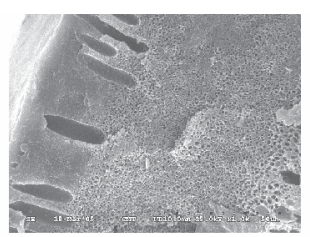

(b)

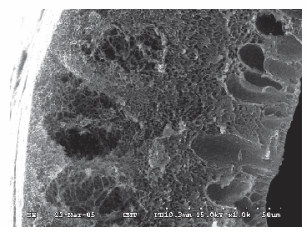

(f)

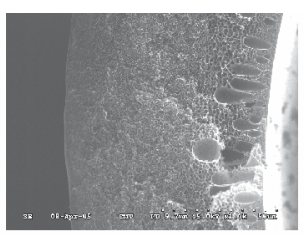

(c)

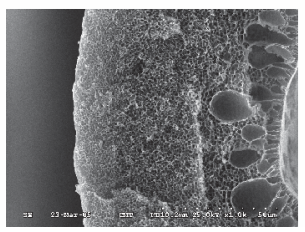

(g)

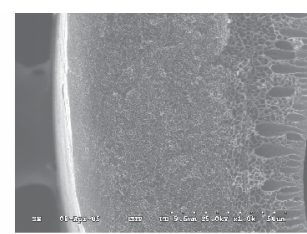

(d)

Fig. 1. Cross-sectional membrane morphology of the polysulfone (PSf) hollow fiber prepared with an ambient relative humidity of $90 \%$. Air gap: (a) $0 \mathrm{~cm}$, (b) $2.5 \mathrm{~cm}$, (c) $5 \mathrm{~cm}$, (d) $7.5 \mathrm{~cm}$, (e) $10 \mathrm{~cm}$, (f) $20 \mathrm{~cm}$, (g) $30 \mathrm{~cm}$.

Table 1

The relationship between macrovoids and air gap under different relative humidity

\begin{tabular}{llll}
\hline $\begin{array}{l}\text { Relative } \\
\text { humidity }\end{array}$ & $\begin{array}{l}\text { Macrovoids first } \\
\text { suppression } \\
(\mathrm{cm})\end{array}$ & $\begin{array}{l}\text { Macrovoids } \\
\text { reappeared } \\
(\mathrm{cm})\end{array}$ & $\begin{array}{l}\text { Macrovoids } \\
\text { resuppression } \\
(\mathrm{cm})\end{array}$ \\
\hline $30 \%$ & 10 & 20 & 50 \\
$70 \%$ & 10 & 20 & 40 \\
$90 \%$ & 5 & 10 & 30 \\
\hline
\end{tabular}

the air gap, the disappearance and reappearance of macrovoids occurred at a shorter air gap.

One possible reason for the disappearance of macrovoids is an increase in the solution viscosity due to water intake in the air gap. Another possible mechanism is the gelation of the polymer-rich phase after VIPS. The formation of a gel layer in the air gap can inhibit the fast exchange of solvent and nonsolvent in the coagulation bath and suppress the macrovoids. However, with a longer air gap, the macrovoids reappeared because the phase separated region was no longer gelled after enough time was given for polymer relaxation. The macrovoids totally disappeared when the air gap was long enough to allow phase separation, before the dope reached the coagulation bath.

\subsection{Effect of VIPS on the separation performances of PSf hollow fiber membranes}

The morphology of hollow fiber membrane can affect the separation performances. Fig. 2 reveals the pervaporation performances of $90 \mathrm{w} \%$ aqueous isopropanol solution through $90 \%$ relative humidity spun PSf hollow fiber membranes under various air gap. It shows that the water content in permeate increases, then decreases, and increases

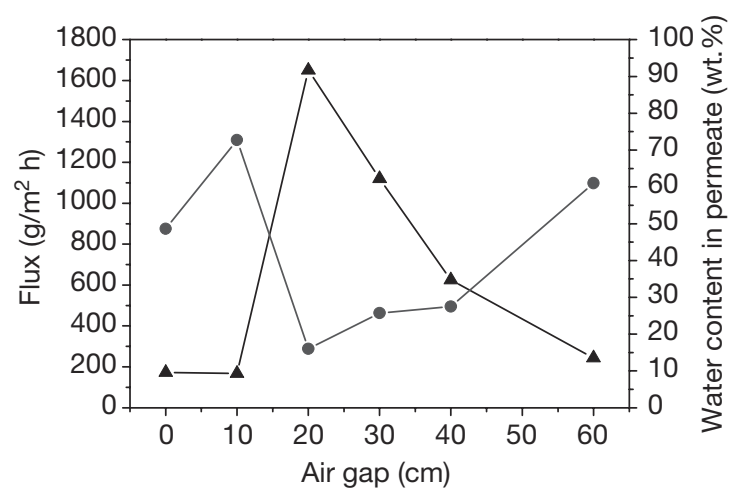

Fig. 2. Effect of air gap on the pervaporation performance of polysulfone (PSf) hollow fiber membrane. ( $\mathbf{\Delta})$ flux, (๑) water content in permeate. 


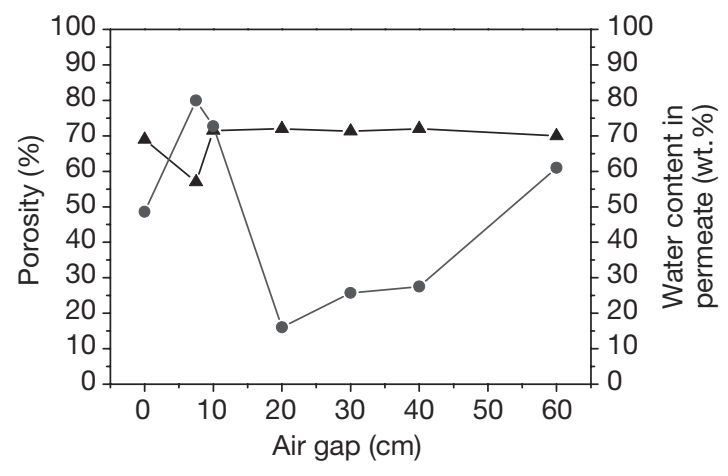

Fig. 3. Effect of air gap on the porosity ( $\mathbf{\Lambda}$ ) and water content in permeate $(\bullet)$ of polysulfone (PSf) hollow fiber membrane.

again while the flux decreases, then increases, and decreases again as the air gap increases. Fig. 3 depicts the porosity and water content in permeate under various air gap. It shows that the porosity of hollow fiber membranes decreases as the air gap increases to $7.5 \mathrm{~cm}$. It increased again as the air gap increased to $10 \mathrm{~cm}$ and then leveled off.

\section{Conclusions}

PSf hollow fiber membranes were fabricated by a dry/wet spinning process. The morphology and separation performances of the fibers were found to be strongly affected by air gap and ambient humidity. Macrovoids in the membranes disappeared, reappeared, and redisappeared with increasing air gap. The air gap required for the suppression and resuppression of macrovoids decreased with increasing ambient humidity.

\section{Acknowledgements}

The authors sincerely thank the Ministry of Economic Affairs and the National Science Council in Taiwan, ROC, for providing financial support for this work.

\section{References}

[1] M.H.V. Mulder, Basic Principles of Membrane Technology, Kluwer Academic Publishers, London, 1996.

[2] H. Matsuyama, M. Teramoto, R. Nakatani and T. Maki, Membrane formation via phase separation induced by penetration of nonsolvent from vapor phase. I. Phase diagram and mass transfer process, J. Appl. Polym. Sci., 74 (1999) 159; II. Membrane morphology, J. Appl. Polym. Sci., 74 (1999) 171.

[3] V.P. Khare, A.R. Greenberg and W.B. Krantz, Vapor-induced phase separation - effect of the humid air exposure step on membrane morphology Part I. Insights from mathematical modeling, J. Memb. Sci., 258 (2005) 140. 